\title{
Alteridade, diálogo e direitos humanos: Desafios formativos no cenário atual e a perspectiva do interhumano em Martin Buber ${ }^{1}$
}

\author{
SANTIAGO, Maria Betânia do Nascimento ${ }^{2}$ \\ $R O ̈ H R$, Ferdinand ${ }^{3}$
}

\begin{abstract}
Resumo
A experiência formativa envolve um amplo leque de questões que tornam o filosofar sobre a educação um grande desafio, especialmente considerando o atual cenário das sociedades contemporâneas. É tarefa de uma filosofia da educação o exercício do pensar sobre essa realidade, que se encontra marcada pela negação de princípios fundamentais à humanização. Nela a afirmação da diferença se configura como um problema, que se alia às formas de indiferença e à ausência de vínculos entre as pessoas. Esse quadro tende a impulsionar o fenômeno da violência, do qual se ocupa o debate sobre os Direitos Humanos. É neste cenário que podemos compreender a exigência de refletir sobre alguns conceitos, e que situamos a problemática da alteridade, como afirmação da essencial diferença do outro. A partir dessa realidade indagamos sobre o papel da educação na constituição de relações mais solidárias no mundo, como possibilidade de que no interior da instituição educativa se compreenda a relação com o outro como modo de ser e sentido do ético. O olhar lançado a essas questões assume as contribuições da antropologia do interhumano de Martin Buber, que, ao reconhecer o primado da relação, do diálogo, nos leva ao sentido do educativo e aos desafios à formação humana em nosso contexto. Desse modo, o trabalho busca articular a problemática anunciada às contribuições advindas dessa filosofia do diálogo, pelo que essa experiência pode oferecer de significativo à compreensão e enfrentamento das questões em pauta, como exigência que se coloca à educação em nossos dias.
\end{abstract}

Alteridade. Diálogo. Direitos Humanos. Formação Humana. Martin Buber.

\section{Resumen}

La experiencia formativa implica muchas cuestiones que hacen del filosofar sobre la educación un gran desafío, especialmente considerando el actual escenario de las sociedades contemporáneas. Es tarea de una filosofía de la educación el ejercicio del pensar sobre esa realidad, que se encuentra marcada por la negación de principios fundamentales a la humanización. En ella la afirmación de la diferencia se configura como un problema, que se une a formas de indiferencia y ausencia de vínculos entre las personas. Este cuadro tiende a impulsar el fenómeno de la violencia, del que se ocupa el debate sobre los Derechos Humanos. Es en este escenario que podemos comprender la exigencia de reflexionar sobre algunos conceptos, y que situamos la problemática de la alteridad, como afirmación de la esencial diferencia del otro. A partir

\footnotetext{
1 Trabalho apresentado no V Colóquio Internacional SOFELP - Sociedade de Filosofia da Educação de Língua Portuguesa - "Migrações, Cidadania e Direitos Humanos: Um puzzle para a Educação", realizado em Vila Real, Portugal (2016).

2 Professora da Universidade Federal de Pernambuco - Núcleo de Formação Docente/Centro Acadêmico do Agreste e Mestrado em Direitos Humanos (CAC) - e-mail: santiagocosta@uol.com.br.

3 Professor da Universidade Federal de Pernambuco - Programa de Pós-graduação em Educação - email: frohr@uol.com.br.
} 
de esa realidad indagamos sobre el papel de la educación en la constitución de relaciones más solidarias en el mundo, como posibilidad de que dentro de la institución educativa se comprenda la relación con el otro como modo de ser y sentido del ético. La mirada puesta en estas cuestiones asume las contribuciones de la antropología del interhumano de Martin Buber, que, al reconocer el primado de la relación, del diálogo, nos lleva al sentido del educativo y a los desafíos de la formación humana en nuestro contexto. De este modo, el trabajo busca articular la problemática anunciada a las contribuciones provenientes de esa filosofía del diálogo, por lo que esa experiencia puede ofrecer de significativo a la comprensión y enfrentamiento de las cuestiones en pauta, como exigencia que se plantea a la educación en nuestros días.

Alteridad. Diálogo. Derechos humanos. Formación Humana. Martin Buber.

\section{Introdução}

As significativas mudanças ocorridas nas últimas décadas, deram lugar a um contexto marcado pela emergência de novos atores sociais, e colocam em evidência questões que vão além da problemática religiosa e étnica, algumas das quais ainda não suficientemente tematizadas. Nesse cenário evidencia-se com mais força o debate sobre a diferença, que ganha novos contornos, pois ele abriga o significado de distintos "modos de ser", expressão da singularidade do humano, no ser mulher, ser homem, ser negro; nas condições de vivência dessa condição, no ser imigrante - africano, boliviano, haitiano, no caso do Brasil, ou advindos de outros continentes para a Europa.

Essa realidade nos convida a pensar no sentido da condição humana, cobrando de nós resposta para perguntas clássicas como aquela que move a antropologia filosófica: que é o homem? Ainda podemos falar em humanidade ou "humanidades"? O que nos humaniza? Algumas das respostas historicamente constituídas podem já não representar essa realidade, ao passo que é possível encontrar, na própria tradição, uma via para compreender o sentido dessa condição humana. De qualquer forma, o caráter multifacetado dessa realidade requer de nós a ruptura com polarizações e uma atenção especial à problemática da alteridade e de uma ética que faça justiça ao outro, e, acima de tudo, capaz de acolhê-lo e acolhê-la.

Isso significa assumir um agir capaz de responder à face nova de cada situação, e que assim possui exigências próprias, singulares ao momento, reconhecendo que o ético se constitui unicamente numa relação com a pessoa, e não na indiferença anônima. Pois, se o atual contexto ainda se revela negador da diferença, da afirmação da singularidade, esbarramos num quadro crescente de indiferença, outra face do mesmo fenômeno, e cujos desdobramentos podem levar à destruição daquilo que propriamente nos caracteriza como humanos. Nesse caso, é emblemático o alerta feito por Adorno (1995), em sua análise sobre o que tornou possível a aceitação da barbárie de Auschwitz, assinalando os riscos da indiferença aos outros, expressão e via de legitimação da violência, que manifesta a ausência de 
vínculos entre as pessoas e de consciência. $\mathrm{E}$, de modo emblemático, o olhar que Martin Buber (1878-1965) lança a problemática, denunciando o retraimento do interhumano, da vida entre pessoa e pessoa, e, dessa forma, o crescimento do mundo do Isso.

Os problemas que se afiguram colocam em evidência conceitos fundamentais ao debate filosófico, a exemplo do sentido da diversidade, da singularidade e da universalidade, que, sendo mais do que termos, expressão modos próprios de ser no mundo; envolve mais do que um exercício contemplativo, em razão dos seus desdobramentos práticos, no sentido das atitudes e dos princípios orientadores, pressupondo que consigamos ir além da mera tolerância. Essa realidade é negadora de uma vida plena, pela rejeição de princípios fundamentais à humanização, constitui-se numa problemática singular ao campo dos direitos humanos, e, a partir desse lugar, podemos compreender os desafios à formação humana em nossos dias.

Dessa forma, compreendemos que a experiência formativa nas sociedades contemporâneas envolve um amplo leque de questões que tornam o filosofar sobre a educação um grande desafio. Por esse ângulo, a questão da alteridade, como essencialmente a diferença do outro, tem adquirido centralidade no debate educativo, revelando ao mesmo tempo o paradoxo de uma realidade, na qual as manifestações extremistas de xenofobia, homofobia, racismo, expressam a negação explícita da diferença; da mesma forma que o seu reverso, com a generalização da indiferença ao que ocorre no mundo, na frieza que marca as relações humanas.

É nessa realidade que cabe um especial e complexo papel à educação, no sentido de contribuir para a construção de novas e significativas relações no mundo. Ela pode se configurar em momento privilegiado para o encontro; o voltar-se para o outro como ele é; reconhecendo que, no interior da instituição educativa, pode-se compreender o sentido de ser no mundo, como seres de relação que somos. Nesse aprendizado revela-se a importância fundamental de afirmar a alteridade, como movimento ético de reconhecimento do outro e de responsabilidade pelo mundo. O olhar lançado a essas questões, assume as contribuições da filosofia do diálogo de Martin Buber, sua antropologia do interhumano, que orienta uma fenomenologia das relações e que assinala significativos desafios à formação humana.

A partir desse viés, situamos o debate sobre a alteridade e os desafios que se apresentam nos dias atuais, em um contexto ainda marcado pela negação do outro, no qual se manifestam formas diversas de violação de direitos humanos fundamentais. A reflexão proposta toma como referência a filosofia do diálogo de Martin Buber, que afirma o primado da relação, como possibilidade de compreensão desse fenômeno e assume o desafio de articular essa leitura ao âmbito educativo, reconhecendo que a experiência formativa pode oferecer elementos significativos à compreensão e enfrentamento da 
problemática, e seus desdobramentos no fenômeno da violência, como questão que toca os Direitos Humanos.

\section{Os direitos humanos e os desafios da diferença}

O que se denomina direitos humanos resulta de conquistas históricas, e, mesmo sendo um conceito marcado por paradoxos em sua efetivação (ARENDT, 1989, p. 324), expressam a luta pela dignidade humana. O reconhecimento desses direitos, resulta de um amplo esforço pelo estabelecimento de "parâmetros balizadores das ações das diferentes culturas com relação ao que considera como razoável quanto ao respeito aos direitos fundamentais dos seres humanos" (BRASIL, 2006, p. 15). Da mesma forma, a adesão por essas populações e seus representantes reflete a consciência ética contemporânea, simbolizando certo grau de consenso internacional a respeito de temas centrais aos direitos humanos e a universalidade deles.

Reconhecer esses direitos como universais é afirmar a dignidade de todo ser humano. Mesmo que essa universalidade seja vivenciada em tempos e lugares específicos, sendo por isso histórica, há elementos dessa condição humana que compartilhamos e que nos unifica. É dessa forma que se pode compreender o reconhecimento do "direito à vida", como núcleo fundamental e pressuposto dos Direitos Humanos. Esse também é um valor histórico, que evoluiu com o tempo e lugar, que assim pode ser eventualmente contestado, dada as especificidades culturais e os contornos peculiares à situação. Com efeito, falar em direito à vida vai além do "não matarás", no sentido literal do termo, pois se pode matar alguém, ou tornar-se detentor do direito à vida em diferentes situações, como escravidão, trabalho forçado, cárcere privado, ou negar o primado da dignidade da pessoa humana.

Afirmar o caráter inalienável da pessoa humana é reconhecê-la como um fim em si mesma, princípio que se sustenta na ideia de dignidade humana. Tal reconhecimento demarca o caráter ético-valorativo dos Direitos Humanos, sustentados por um conjunto de valores que adquirem consensualidade e que podem se converter em princípios éticos, possíveis de serem compartilhados, como expressão daquela responsabilidade do mundo comum de que nos fala Arendt (2014), que torna necessária a prática educativa, para introduzir as novas gerações nesse mundo - âmbito dos saberes, valores, princípios, e que assim também se apresenta como tarefa da educação.

Pensar essa relação entre ética e direitos humanos em nossos dias resulta numa tarefa complexa, pois se, por um lado, cabe reconhecer a universalidade dos direitos, por outro, essas garantias se estabelecem em um cenário marcado pela ruptura com princípios universais. Evidencia-se aí a contradição de lidar com a diversidade do mundo e a exigência de constituir um horizonte comum. Nesse caso, como estabelecer critérios para uma ação comum, numa realidade multifacetada? Como falar em cidadania, ou sobre 
qual cidadania pode-se falar em um contexto global? Como aplicar o ideal de universalidade em um mundo plural como o nosso? Ainda seria possível falar em humanidade ou humanidades? Como pensar e construir modos de vida mais humanos, assumindo que somos múltiplos? Essas questões fazem parte da trajetória dos Direitos Humanos, revelando sua "evolução" no que pese às conquistas e desdobramentos teórico-práticos.

As mudanças ocorridas nas últimas décadas e a emergência de novos destinatários dos direitos têm revelado o caráter insuficiente, genérico e abstrato do discurso sobre a universalidade, alicerçado no reconhecimento da dignidade de todo ser humano e na afirmação do princípio da igualdade. Nesse cenário, a afirmação do direito à igualdade se conjuga com a defesa do direito à diferença. Contudo, o próprio debate sobre a diferença ganha novos contornos, como possibilidade de promoção daqueles/as que se encontram à margem: a mulher, os homossexuais, os negros e indígenas, as crianças, os segmentos sociais marginais, etc. Assim, a afirmação da igualdade como direito universal marca uma polêmica que revela distintas perspectivas e relaciona o ideal de justiça ao reconhecimento das identidades.

Este não é um problema meramente conceitual, pois afirmar igualdade significa reconhecer a universalidade de direitos e deveres, não havendo pessoas privilegiadas, a ponto de ter maior acesso a benefícios negados a outros, nem pessoas isentas de responsabilidades coletivas. Consoante este princípio, o sujeito de direitos é portador de uma condição singular, tem direito à diferença, no que se refere a aspectos individuais, como a questão de gênero, as questões relacionadas aos limites físicos ou cognitivos, assim como de ordem cultural mais ampla, como a pertença a determinada etnia, etc.

Dessa forma, a problemática da diferença revela-se complexa, no que pese às reivindicações em pauta, mas também ao sentido de que elas guardam os desdobramentos possíveis. Nessa perspectiva, Bauman (2003) reflete sobre um quadro de abandono do modelo de justiça social por algumas leituras em Direitos Humanos, e que evidenciam a polarização entre as "demandas por redistribuição", relativas à igualdade, com as "demandas por reconhecimento", expressão do abandono no "modelo de justiça social" (p. 69). Quanto a isso, alerta para o risco da "falsa escolha", pois a afirmação da diferença, situada no âmbito dos direitos individuais, não se compreende fora da garantia ao bem-estar e a uma vida digna. E quanto a isso, não se trata de estabelecer uma hierarquia, priorizando um aspecto em detrimento do outro, pois o direito ao "reconhecimento" é uma questão urgente à democracia, tanto quanto a vivência plena dos direitos sociais e econômicos, como no respeito à dignidade humana. Dessa forma, a afirmação da diferença se articula à universalização de garantias historicamente negadas a determinados segmentos sociais. 
Essa questão envolve um debate no qual a filosofia se aventura, por meio de uma abordagem antropológica e ética, na busca do sentido da experiência humana. Emerge desse olhar sobre a problemática da diferença uma leitura desafiadora ao nosso contexto, com possibilidade do relativismo a que a absolutização da diferença pode levar e o risco da generalização da indiferença. Questão assinalada por Adorno (1993), há algumas décadas, em Minima Moralia, ao referir-se à dialética da civilidade (tato). Assinalando a identidade entre civilidade e humanidade, argumenta que aquela vai além do "refinamento ou do gosto", como possibilidade de que a experiência social possa se estabelecer a partir do "prisma da consideração do outro, naquilo que ele tem de universalmente válido". Nessa linha, Cohn (2004, p. 84) afirma:

[...] a consideração pela humanidade do outro não é abstrata, mas passa pela diferença que o individualiza. É, pois, o oposto da indiferença. Mas também não é mera diferença, distinção solta, desencadeada: sua referência é universal, como possibilidade a ser cobrada como promessa, na figura de uma humanidade unidas nas suas particularidades, reconciliada.

A preocupação com o relativismo deve-se ao risco de que esta situação contribua para a fragmentação de aspectos comuns, levando à homogeneização, pois "onde só há diferenças o resultado é o indiferenciado" (COHN, 2004, p. 84). O autor alerta para o caráter insuficiente da legitimação do outro como diferente, pois, "o tão decantado respeito pelo outro não rompe o círculo perverso do confronto do particular com o particular, em que cada qual fica do seu lado na sua irredutível diferença" (COHN, 2004, p. 85). Mais que isso, a afirmação da diferença pode encobrir a generalização da indiferença, que Adorno constatou como barbárie, como "uma forma perversa de universalização: tudo o que não se identifica com a peculiaridade dada é resto indiferenciado, irrelevante, indiferente, portanto" (COHN, 2004, p. 85).

Esse discurso de legitimação do outro pode nos encaminhar para uma temporária zona de conforto, no qual se encontra a ideia da tolerância, que tanto incomodou Martin Buber, em sua experiência pessoal como judeu, a partir da qual ele se refere ao risco da "mútua tolerância sem mútuo entendimento". E acrescenta: "não lembro de nenhum professor que não fosse tolerante, ou, então, que não quisesse passar por tolerante" (BUBER, 1991, p. 15). Porém a prática educativa revelava-se como um contrassenso, e, desse modo, o fato de ser um "convidado forçado" a participar das cerimônias religiosas, teve mais força que a intenção. E, dessa forma, acrescenta: "Isto gravou-se no mais profundo do ser daquele rapaz" (BUBER, 1991, p.16). Nesse sentido, é significativa a afirmação do Rabino Nilton Bonder, que, numa escrita menos convencional ao mundo acadêmico, demarca a aceitação da 
diferença como medida para a própria liberdade. E nos alerta para o risco de confundirmos o reconhecimento do outro com a tolerância:

Tolerar é um esforço para conter o desprezo e a indignação. Isto em si não gera liberdade, mas cria uma convivência tensa, pronta a ser rompida com violência e preconceito. A liberdade depende da apreciação. Ou seja, da profunda consciência de que a diferença do outro é a verdadeira guardiã de nossa liberdade. A liberdade começa em casa, passa por nossos amigos e termina no respeito ao estranho. (BONDER, 2010, p. 49-50).

Dessa forma, é importante reconhecer a complexidade das formas de violência, manifesta na intolerância ao outro, e que, paradoxalmente, não se resolve pela mera tolerância. Pelo contrário, tolerar como expressão de uma certa indiferença, tende a corroer a possibilidade de vínculo autêntico entre as pessoas. Decerto, importa aqui superar o pessimismo adorniano, que, referindo-se Goethe, assinala a "impossibilidade de quaisquer relações humanas na sociedade industrial emergente" (ADORNO, 2008, p. 32). Até mesmo porque há outros sentidos para a tolerância, como a perspectiva anunciada por Lessing, mas nele, como destaca Arendt (2008, p. 35), essa ideia "tem pouco a ver com a tolerância no sentido habitual (...), mas muitíssimo com o dom da amizade, com a abertura ao mundo e, finalmente com o verdadeiro amor à amizade". Importa ainda perguntar, como faz Bonder (2001, p. 43): o que é tolerável e o que é intolerável? Depende da situação. Mas, certamente, o "intolerável não é a diferença, mas a indiferença".

Assim, a afirmação da diferença no debate filosófico sobre a alteridade, ao mesmo tempo que se distancia da ideia de tolerância, vai além do problema da identidade ou da garantia de direitos, mesmo que não os dispense, constituindo-se numa problemática que move a condição humana, de ser outro, e assim deve ser enfrentada com os desdobramentos que the são próprios. Com isso, apresentamos a seguir uma leitura da filosofia do diálogo de Buber, tomando essas inquietações como referência para compreender a problemática, situando-a no âmbito da relação.

\section{Primado da relação na filosofia do diálogo de Martin Buber}

As questões apontadas encaminham para a compreensão do que torna possível a humanidade ou "humanidades". Buber (1994) parte do pressuposto da condição de essencial diferença do humano, como modo de ser e pressuposto para o encontro. Essa condição é vivida pelos seres humanos em relação aos outros seres e constitui um duplo movimento: a distância, como experiência de contraste com o outro, e a relação, como possibilidade de 
vínculo entre as pessoas. Temos na distância uma condição antropológica originária e fundamental, mas não um ato; o ato primordial é a relação. Ou seja, o impulso de interligação na vivência originária fundamenta a precedência da relação, ao mesmo tempo a torna uma exigência, pois o "homem se torna $E u$ na relação com o Tu", afirma Buber (1979, p. 32). Portanto, somente na medida em que encontra um $T u$, e Ihe endereça a palavra, realiza a possibilidade essencial de humanização.

Assim, a distância (Distanz), como expressão da multiplicidade do mundo, é um pressuposto para entrar-em-relação na medida em que possibilita que cada um dos envolvidos se apresente de forma autônoma. Mas dessa condição de autonomia não decorre, desde já, a entrada na relação, pois Distância e Relação, sendo peculiaridades do humano, em sua duplicidade de princípio, não podem ser tomadas como dois aspectos de um mesmo processo, não havendo uma relação de causa e efeito. Mesmo que o primeiro seja um pressuposto para o segundo, este não é uma consequência do primeiro. Ou seja, a distância oferece o espaço para o surgimento da relação, mas ela não necessariamente se concretiza.

Cabe ainda salientar que, na esfera das relações interpessoais, assim

como a vida social, o conflito se interpõe como problemática e componente dessa dinâmica, pois cada um desses movimentos vê o outro como obstáculo à sua realização: a distância encontra-se ameaçada pela relação, que pode levar a uma fusão e à consequente diluição das diferenças; da mesma forma, a relação vê-se continuamente ameaçada de não se efetivar pela exigência do singular (BUBER, 1994, p. 284). Tal condição permite compreender o sentido da comunicação entre as pessoas, uma vez que diálogo é reciprocidade; a afirmação da diferença é uma garantia de que ele não se configure como monólogo. Sendo a linguagem o elemento distintivo e testemunho da nossa humanidade, "o dirigir a palavra se funda no fato de pôr-se e reconhecer a autônoma alteridade do outro com o qual, propriamente por este motivo, se está em relação, interrogando e respondendo" (BUBER, 1994, p. 289). Enquanto efetivação da relação entre os homens significa a aceitação da alteridade.

Quando dois homens [pessoas] trocando suas opiniões, profundamente diferentes, a respeito de um objeto, cada um com a intenção de convencer o interlocutor da justeza de seu ponto de vista, por mais que considere o sentido do ser humano, tudo depende do fato que cada um entenda o outro como ele é, que a saber, mesmo com todo o desejo de influenciá-lo, o aceita e o confirma sem reservas no seu sereste-homem-aqui, o seu ser-fato-assim. (BUBER, 1994, p. 289190). 
Esse reconhecimento não significa necessariamente concordância, que, em verdade, é "um mero acaso da compreensão". Mais do que apostar na aceitação de um ponto de vista, importa reconhecer a legitimidade da diferença, de um modo de ser. A questão pode ser compreendida a partir da premissa básica que orienta a condição de alteridade do humano, como exigência de reconhecimento pelo outro. Buber (2009) esclarece essa questão com a problemática da aparência, que limita às relações autênticas, reconhecendo a dificuldade de confirmação como elemento capaz de gerar o desejo de aparentar algo que não se é. Em geral, optamos pela imagem aceita e nos distanciamos da nossa singularidade. Isso porque não basta ser diferente, pois como humanos nos realizamos na conquista da "presença no ser do outro" (BUBER, 1994, p. 292), ele assim caracteriza essa realidade:

A tão difundida tendência de viver a partir da diversidade da impressão causada. (...). Ela se origina de fato no avesso do próprio inter-humano: na dependência dos homens entre si. Não é fácil fazer-se confirmar no seu Ser pelos outros; aí a aparência oferece a sua ajuda. (BUBER, 2009, p. 144).

A confirmação é resposta a um apelo que me é dirigido; encontro que se realiza entre seres concretos; acontecimento singular, e não mero dever. Ela é a condição para o diálogo, que pressupõe dos envolvidos a disposição para aceitar o outro como ele é; um "tomar-se presente", que resulta do "conhecimento íntimo", como experiência da totalidade vivida na concretude. Quanto a isso, assinala que ele decorre da "relação com o outro, portanto quando ele se torna presença para mim. É por isso que designo a tomada de conhecimento íntimo neste sentido especial como o tornar-se presente da pessoa" (BUBER, 2009, p. 146).

Assim, a ontologia do interhumano de Buber representa uma significativa leitura do mundo contemporâneo reveladora do fracasso do homem em assumir um modo de vida mais humano. A tese fundamental dessa filosofia se encontra na obra Eu e Tu (1923), na qual ele defende o caráter dialógico do humano, que transcende a sua condicionalidade na medida em que, por um ato de liberdade, se lança na relação com o outro. A ontologia e antropologia do interhumano caracteriza a condição humana pela dupla atitude, expressa nas palavras-princípio Eu-Tu e Eu-Isso. São atitudes que fundamentam a existência do $E u$, que se constitui na relação ora com um Tu, ora com um Isso. Dessa forma, afirma Buber (1979, p. 4): "Não há Eu em si, mas apenas o Eu da palavra-princípio Eu-Tu e o Eu da palavra-princípio Eu-lsso". De um lado, a vida no Isso encontra-se marcada pela objetivação, experimentação; e do outro a relação, como expressão do dizer Tu. A relação Eu-Tu é essencialmente gratuidade, mas uma graça que não é mero "acaso", uma vez que pressupõe 
abertura, disponibilidade para vivenciá-la. O endereçar a palavra ao outro "é um ato de meu ser, meu ato essencial", afirma Buber (1979, p. 12).

Um elemento distintivo da relação é sua oposição à experiência, que implica um "saber" sobre algo/alguém; entre o Eu e as propriedades do outro. Diferentemente, a relação ocorre entre o Eu e o Outro como totalidade, não havendo lugar para perguntas acerca de suas características, pois no momento em que alguém se torna meu Tu, suas qualidades deixam de ser relevantes. Numa crítica aos relacionamentos que predominam no mundo contemporâneo, Buber (1979, p. 9-10) alerta que a pessoa não pode ser confundida com um objeto a ser manipulado, dada a irredutibilidade humana a tal condição, numa crítica a "um olhar analítico, redutor e dedutivo" que predomina na relação entre as pessoas (BUBER, 1982, p. 147). Nessa direção, o encontro (Begenung) é algo que transcende às formas de classificação, de enquadramento do humano, a exemplo da moral, estética e outros juízos que possamos fazer do outro, pois a relação se estabelece com a pessoa mesma.

Esse direcionamento oferece-nos um olhar para a problemática da alteridade segundo a dialógica. A partir dele podemos compreender melhor a nossa dificuldade de aceitar o outro como ele é. $\mathrm{Na}$ maioria das nossas recusas a uma conversação genuína, o que se coloca como verdadeira questão, não é a discordância em relação a determinado fato ou ponto de vista, mas a recusa em aceitar o outro, de confirmá-lo na sua singularidade. Esse desejo de influenciar o outro pode se converter em negação da individualidade, nosso empenho em modificar o outro, pela inculcação de uma verdade: a "minha própria certeza" (BUBER, 1994, p. 290).

Tais questões assumem especial relevância, como indicativos de uma vivência humanizante, assim como o seu contrário, revelando-se como forma de violência, como "forma de morte" do outro; como violação do ser singular, que extrapola o âmbito jurídico, mesmo aquele dos direitos humanos. Não há violência maior do que negar o outro, pela incapacidade de acolhê-lo em sua singularidade. Tal realidade fere um postulado básico da vida e sua materialização em uma comunidade humana: a possibilidade de seus membros se confirmarem mutuamente em razão da sua diversidade. Somente na medida em que se reconhece a diferença como possibilidade de conviver com outros, de entrar em relação, uma sociedade pode ser chamada humana.

Enquanto humanos, encontramo-nos também no reino da liberdade, que requer sempre de nós o ato de decisão. Assim, o sentido da liberdade na esfera do interhumano, como resposta ao outro como responsabilidade para com o mundo, efetiva-se na existência concreta. A liberdade é então compreendida como possibilidade de se vincular, de vivenciar o encontro. Sendo o humano ser de relação, nela se encontra a possibilidade da realização plena no mundo, de seres aos quais está sendo dirigida a palavra, e, pela interligação, tornam-se seres que respondem. Esse agir ético é 
fundamentalmente da ordem do singular, pois, mesmo que o critério que orienta a decisão seja anterior àquele momento, ela se efetiva como em uma situação particular, como resposta ao apelo de uma realidade concreta.

Impõe-se, ainda, a exigência de que tal decisão brote do íntimo da pessoa. Essa é a condição para o reconhecimento do certo e do errado, a ser considerado sempre em relação a determinadas circunstâncias. Nesses momentos a exigência maior é a capacidade de distinguir um do outro, reconhecendo que o agir ético se constitui unicamente numa relação com uma "segunda pessoa" e não na indiferença. O sentido de tal agir e da liberdade que o constitui só é possível em uma experiência de vínculo mútuo entre os humanos, cujo nome é Comunidade. Decantada e negada, ela continua sendo o modo de viver no mundo, mesmo que não possamos mais - não sendo esta a questão - resgatar formas primárias dessa experiência. Há que se reconhecer um novo sentido para a comunidade, que nos permite também compreendê-la como resposta ao desafio a uma "nova cidadania" nesse contexto, que possa nos afastar do risco da desumanização.

\section{Interhumano e formação ou uma educação para a comunidade}

A antropologia do interhumano conduz a uma fenomenologia das relações, configurando-se como referência para o sentido da relação educativa.

Nela, autonomia pessoal e a colaboração mútua constituem-se na referência segundo a qual se pode compreender a vida em comum, em razão do fato de que os homens se ligam e se unem a partir de laços mútuos, como "pessoas ao mesmo tempo dependentes e independentes entre si" (BUBER, 2009 , p. 20). A esfera interhumana evoca o caráter intersubjetivo do Eu, que se constitui na relação com o outro, na interdependência com a comunidade: "Ambos, eu e comunidade, realizando-se no encontro dialógico, são interdependentes e 'equifundantes' da existência humana" (ZUBEN, 2003, p.17).

Considerando que a autêntica comunidade requer a educação, Buber (2012) argumenta que essa pressupõe uma ação realizada por pessoas que vivem o sentido de comunidade, que manifestam em si mesmas este sentido: "Educação é uma preparação para o sentido de Comunidade, na vida pessoal e com a vida pessoal, introduzindo a partir desta vida naquilo que existe hoje na sociedade" (p. 89). A educação visa possibilitar a consolidação de atitudes e valores reconhecidamente humanos e humanizantes, que se constituem no chão fértil da vivência no seio da própria comunidade. Nesse sentido, afirmar a comunidade como um pressuposto para o essencialmente educativo significa reconhecer que somente a vida autêntica pode gerar autenticidade. $E$ mais: sem essa espontaneidade, sem a direta correspondência com a existência pessoal não há educação, por melhor estruturada que ela pareça, por mais ilustre que seja o educador, pois "educar para a comunidade só é possível na 
medida em que existe comunidade que educa para a comunidade" (BUBER, 2012, p. 90). Trata-se da autêntica vida de relação entre seus membros, na existência desses núcleos constituidores e legitimadores dessa forma de vida.

Quanto a isso, a questão mais urgente e complexa é saber das possibilidades e das condições de a escola assumir uma educação para a comunidade, reconhecendo nesse modo de vida uma referência concreta à qual o educador pode se reportar para realizar algo singular em nossa época. Por certo, a questão fundamental é a decisão pessoal que caracteriza a ação educativa. É partindo desse princípio que Buber aponta os limites e as possibilidades dessa educação em seu contexto. Quanto a isso, ele define a educação para a comunidade como relação, reconhecendo que educar é formar pessoas para a capacidade de estabelecer relações autênticas entre si. Uma tarefa a ser realizada já na infância, em razão dos mecanismos a partir dos quais se estruturam as sociedades.

O compromisso com essa formação pressupõe a superação de uma visão meramente adaptativa dos indivíduos às exigências sociais, que assuma como condição a formação de uma consciência unificada, capaz de lidar com as situações singulares, buscando, na medida do possível, estender essa experiência de comunidade para as esferas sociais. A definição, ao mesmo tempo em que nos deixa entrever o sentido da educação, também caracteriza a relação, enquanto núcleo essencial do educativo. Ela é o meio e o fim, o telos do processo educativo. É a relação dialógica de um Eu e um Tu, como possibilidade do autêntico e genuíno vínculo com o outro, a quem nos dirigimos como Tu: "Para isso é essencial voltar-se para o outro como ele é... para a face vital desta outra pessoa como à sua própria face; que dois seres se tornem presentes mutuamente" (BUBER, 2012, p. 93).

Esse voltar-se para o outro, pressupõe a superação da visão analítica e redutora, assumindo a atitude dialógica, na qual o outro é reconhecido como pessoa, como uma totalidade que se coloca diante da minha face e à qual eu dirijo a palavra, confirmando-a, assim como ela a mim. Essa é "a realidade sobre a qual se fundamenta a autêntica vida em comum dos homens" (BUBER, 2012, p. 94). Os professores assumem um papel central nessa experiência, e dado o caráter pessoal da ação educativa, aponta a necessária responsabilidade de intermediar a relação com o mundo, assumindo a tarefa de construção daquele núcleo comunitário, mesmo reconhecendo o peso da tarefa: "Não esqueço por um momento que é difícil exigir tudo isso do professor, tomado por seus próprios deveres". Acrescenta: "Não conheço outra pessoa que pudesse realizar esta obra” (BUBER, 2012, p. 98).

Importa compreender o significado dessa atuação da escola e especialmente do professor no "modo comunitário" de educar, no primado da educação pela vida, na qual os momentos de convivência espontânea são essencialmente formativos. Neles, ou na ausência de finalidade, aprende-se a 
lidar com sentimentos e atitudes, que dessa forma se convertem em elementos formativos. Nessa relação, a confiança se apresenta como definidora, pois a experiência formativa requer a participação na vida concreta do educando, assumindo a responsabilidade com a sua presença: "Ele pode conduzir à relação direta, tanto quanto possível nesta situação. Pode conduzir do sentimento de se ter uma comunidade para a realização da comunidade, (...)" (BUBER, 2012, p. 100). Essa postura indica o compromisso com uma formação orientada para atitudes e valores, que embora não façam parte do currículo, como disciplina, permeiam a ação educativa; na maneira como se relacionam entre si e com os educandos, revelando o papel de uma ética pedagógica na consolidação de novas relações.

Assim, o educativo se compreende para além da mera instrução, na formação de pessoas para uma existência autêntica, dialógica, abrangendo o domínio do ético, dos valores, como assinala Kluback (1993, p. 238): “ $A$ educação do povo pertence à discussão de valores e tradições, a arena na qual homens e mulheres aprendem como tomar decisões e a se envolver em debates sérios". Nesse caso, a problemática da aplicação requer a pergunta sobre a situação concreta no âmbito do ético. Quanto a isso, a argumentação de Gadamer (1999, p. 471) nos ajuda a compreender esse debate: "Aquele que deve tomar decisões morais é aquele que já sempre aprendeu algo. (...). A tarefa da decisão ética é encontrar o que é adequado na situação concreta, isto é, ver concretamente o que nela é correto e lançar-se nela"

Dessa forma, considerando a complexidade do mundo atual, e os desafios que se apresentam ao homem e à mulher nesse contexto, importa reconhecer a necessidade de "deliberar constantemente, vivendo num crucial dilema, em relação ao mínimo de mal que deve cometer para assegurar sua sobrevivência física, moral, espiritual, social e, do outro lado, do máximo de bem que deve realizar a fim de preservar-se como pessoa humana" (ZUBEN, 2003, p. 18). Nesse cenário, que evidencia a "contradição entre o desejável e o possível", cada indivíduo é impelido a traçar o que Buber denomina de "linha de demarcação entre exigências imperativas e a possibilidade, limitada e relativa, de poder atendê-las" (ZUBEN, 2003, p. 18). É então que se situa o significado da educação, que deve atuar no sentido da formação da "capacidade de juízo e deliberação", que permita ao indivíduo assumir uma posição, em tais situações, "fatídica".

Essa capacidade de julgamento se vale como esquemas, cuja concretização depende da situação particular na qual se atua; à qual se aplica, que, sendo da ordem do singular, não se pode determinar previamente o que é o certo e o que é o errado na sua especificidade. Além disso, é preciso considerar o sentido que orienta esta capacidade de julgar, cuja exigência é o deslocamento para a concretude da situação na qual o outro se encontra. Para isso, o parâmetro é a relação dialógica, a reciprocidade com o outro, a partir da 
qual ele deseja o justo. Esse julgamento, assim, resulta de um vínculo, cuja expressão maior é a amizade, embora nem sempre ele possa ser vivido na reciprocidade. Não é, pois, um acontecimento entre duas consciências, e, por isso, abstrato, mas possui a marca da reciprocidade, a partir da qual, e só nessa perspectiva, o que vem do outro pode fazer sentido. É nisso, certamente que consiste a amizade: uma relação marcada por uma reciprocidade plena e que se efetiva na concreção da situação.

Educar não é um ato mecânico, nem um ato fundamentalmente político; educar é formar seres humanos para o encontro, para uma vivência comunitária; é formar para o vínculo inter-humano. Essa tarefa é inegavelmente complexa; sujeita a percalços, uma vez que diante dele se colocam as forças contrárias, capazes de minar o impulso de interligação. Desse modo, compreende-se que o verdadeiro trabalho formativo é conduzir a uma vivência autêntica, que possibilite a interligação com o mundo; a defesa incondicional da solidariedade, na vida em comunidade, no "agir em conjunto" com os outros, cujo nome é amizade. É este, pois, o sentido da educação: a formação de pessoas capazes de conduzirem suas vidas coerentemente e de se vincular.

Quanto aos desdobramentos, as expectativas em relação ao que anuncia, indaga: "Como entram na vida as pessoas que foram educadas assim? Em que medida levam um sentido de comunidade no âmbito da vida contemporânea"? (BUBER, 2012, p. 100). Essa questão, posta à prova em diferentes momentos, nos quais os educadores e as instituições educativas ousaram em suas propostas pedagógicas, têm evidenciado o fracasso em estender as experiências vividas no interior das instituições educativas aos mecanismos da vida. Buber reconhece esse fracasso, mas demonstra uma convicção quanto às possibilidades advindas de uma educação para a comunidade, e em relação a esta parece guardar grandes expectativas: "No final há muito na potencialidade deste momento, desta multidão humana, uma multidão que se coloca nesta verdadeira situação na qual se inseriu ao sair da escola e para a qual esta escola preparou" (BUBER, 2012, p. 101).

A afirmação otimista também revela a crítica ao tipo de formação que não prepara para uma autêntica inserção no mundo. Mas é inegável que a tarefa do homem no mundo é algo a ser construído na vivência cotidiana, por isso é também uma tarefa da escola. Com isso, a atenção maior dele se direciona à exigência de uma sólida relação pessoal de cada educando, e não tanto na afirmação de feitos extraordinários, pois aquilo que se revela aparentemente despretensioso, ao final, pode oferecer um saldo positivo, em razão das potencialidades da experiência vivida. Consideramos assim o caráter essencialmente ético dessas relações e da experiência formativa assentada no interhumano; essa leitura permite compreender os possíveis caminhos na condução de um modo de vida mais humano, na relação com o outro.

\section{Considerações finais}


A filosofia de Buber se apresenta como possibilidade de compreensão e enfrentamento de questões que tocam a realidade humana. Sendo uma leitura constituída segundo a perspectiva antropológica, e não uma crítica social, ela oferece uma significativa contribuição à interpretação e enfrentamento aos desafios do presente. Essa leitura manifesta o caráter fundamental da situação dialógica, por revelar o sentido do humano e a dimensão ética que perpassa as relações entre as pessoas, que nos permite compreender a negação do outro como forma de violação da dignidade humana.

Esse olhar permite ampliar o sentido atribuído ao debate sobre diferença no debate sobre alteridade no âmbito da experiência formativa, convidando a pensar a ação educativa, no desafio de compreender como a escola oportuniza essa vivência. Em que medida a diferença é reconhecida e assumida nesse contexto? Quando a afirmação da diferença pode nos levar ao mero relativismo, ao indiferenciado? A escola como instituição que atua segundo a lógica de uma sociedade desigual e discriminatória, tende também a reproduzila nas suas práticas, a padronização que anula as singularidades. A mudança nessa realidade resultará de um investimento de ordem teórica e prática, numa experiência que valorize a diferença ao invés da homogeneização. Ela não se constitui por decreto, sendo necessário um trabalho a partir das diferenças.

Nesse caso, assumir a dimensão de alteridade requer o esforço de ir além da mera tolerância nas relações com aqueles/as de quem discordamos ou simplesmente não compreendemos, ante o risco constante de se converter em violência, algumas muito sutis, mas que podem ter um efeito devastador sobre a pessoa. Sobre isso, retomamos o relato da experiência pessoal de Buber (1991, p. 15) em uma escola católica na Polônia, o risco da "mútua tolerância sem mútuo entendimento". Quanto a isso, concordamos com Nilton Bonder (2010, p. 49), ao afirmar que tolerar é um "esforço para conter o desprezo e a indignação", e isto, em si, não gera diálogo, não gera liberdade, criando uma convivência tensa, pronta para ser rompida. Esse desprezo contido, aprisionado, é ferozmente rompido em diversos momentos, nas formas de violência praticada contra os homossexuais, as mulheres, os negros. Nesse caso, mesmo ricos e famosos, jogadores de futebol são vítimas de xingamento nos estádios, seja em um Brasil profundamente miscigenado, seja numa Europa ariana. Essas formas de rejeição do outro, como desdobramentos da recusa em confirmá-lo/a, manifesta por vezes o desejo profundo de extermínio do diferente, do outro, o não-eu e, por isso, não humano.

Assim, a despeito da nossa desconfiança em relação ao caráter instrumental da educação, importa que ela favoreça aos jovens uma experiência formativa que possibilita a vivência da relação com o outro, em vista de uma nova cidadania. Esse ser-cidadão, para além de reconhecer-se como sujeito de direitos e deveres, pressupõe um aprendizado de ser, assumindo princípios, valores, como respeito ao outro, solidariedade e 
responsabilidade para com 0 mundo. A vivência dessas dimensões no processo educativo pode contribuir para uma cultura dos Direitos Humanos, com atitudes voltadas para a promoção e valorização da diversidade e a participação efetiva na sociedade.

Nessa experiência, é importante considerar o papel ativo dos educandos, em sua capacidade de conferir sentido ao que é aprendido, pois os valores e princípios éticos se constituem numa experiência dialógica entre os envolvidos, sendo o próprio diálogo um valor, um princípio orientador na relação com o outro. Cabe à escola atuar na construção desses valores, auxiliando seus membros a um modo de vida pautado no reconhecimento da alteridade. Trata-se de um tipo específico de aprendizagem, pois o ético não pode ser ensinado como outros conteúdos, e não se constitui em nós por natureza, como alertou Aristóteles (1992, 1103b), quanto a impossibilidade de ensinar a virtude ética ou excelência moral, que estaria dependente de uma vivência cotidiana. Essa aprendizagem se alicerça na experiência com 0 mundo; algo que se constrói no dia-a-dia, mediado pelas relações que estabelecemos com os outros, e que depende da qualidade dessas mesmas relações interpessoais assentadas no reconhecimento da dignidade humana, no reconhecimento da condição de alteridade do outro.

Como direcionamento prático, a educação para comunidade, pautada na relação dialógica oferece elementos significativos à compreensão e enfrentamento do fenômeno da violência. Nessa linha, e no que pese ao estabelecimento de novas relações na escola, pautada numa ética da alteridade e do diálogo, impõe-se o aprendizado de um modo de ser não violento, de relações não violentas. Contudo, isso não significa imaginar a escola como o oásis, e que essa experiência possa se configurar sem conflitos, dado o caráter formativo dessas experiências, tanto ao reconhecimento de que eles são inerentes às relações humanas, e não um impedimento a elas, mas, sobretudo, às possibilidades que eles representam ao cotidiano da escola. Tais questões implicam o reconhecimento da alteridade, de seres que, sendo diferentes, não podem evitar o conflito, mas lidar com as situações, buscando superar posturas assentadas numa moral dicotômica.

O debate em torno dos desafios presentes impõe-se como exigência à superação das abstrações, no reconhecimento da realidade com a qual nos deparamos; a superação da forma de pluralidade abstrata, herdada dos ideais modernos. Nesse complexo, ainda marcado por velhas questões, torna-se urgente a manifestação de outros modos de ser no mundo, que podemos até denominar de uma "nova cidadania". Desde que, não aquela local e de caráter nacionalista (como fantasma que vemos ressurgir em vários momentos da história), especialmente reconhecendo a impossibilidade de formas de comunidade limitadas pelo fator geográfico, e compreendendo a possibilidade de "comunidades supra-sociais", como afirmara Buber (2012). 
Essa realidade apresenta-se como desafiadora à educação, e, nesse cenário, a escola assume um papel fundamental, atuando na definição de critérios que norteiam as relações em sociedade, a exemplo a afirmação da dignidade da pessoa humana e do pluralismo ético, valores necessários à vida democrática, como modo de sociabilidade favorável à manifestação das singularidades. Dessa forma, essas questões se constituem em mais do que um convite para pensar sobre o sentido de ser humano nesse mundo, pois o cenário no qual essa experiência se realiza impõe-se à educação como enigma que a mesma, tal como Édipo, precisa decifrar, sob o risco de ver devorado o próprio mundo comum, no qual a ação se desenvolve, para usar uma expressão de Arendt, o mundo efetivo, de que nos fala Buber.

\section{Referências}

ADORNO, T. W. Educação e Emancipação. Tradução Wolfgand Leo Maar. Rio de Janeiro: Paz e Terra. (1995)

ADORNO, T.W. Minima Moralia. Tradução de Gabriel Cohn. Rio de Janeiro: Beco do Azougue. (2008)

ARENDT, H. As origens do totalitarismo. Tradução Roberto Raposo. São Paulo: Companhia das Letras. (1989)

ARENDT, H. Homens em tempos sombrios. Trad. de Denise Bottman. São Paulo: Companhia das Letras. (2008)

ARENDT, H. A Condição Humana. Tradução de Roberto Raposo. Rio de Janeiro: Forense Universitária. (2014).

ARISTÓTELES. Ética à Nicômaco. Trad. de Mário da Gama Kury. 3ª . ed. Brasília: Editora da Universidade de Brasília. (1992)

BAUMAN, Z. Comunidade. A busca por segurança no mundo atual. Tradução de Plínio Dentzien. Rio de Janeiro: Jorge Zahar Ed. (2003)

BONDER, N. Tolerância e o Outro. In. BONDER, N.; SORJ, B. Judaísmo para o Século XX: O rabino e o sociólogo. Rio de Janeiro: Jorge Zahar, p. 43-51. (2001)

BONDER, N. Exercícios da Alma: a cabala como sabedoria em movimento. Rio de Janeiro: Rocco. (2010).

BRASIL. Plano Nacional de Educação em Direitos Humanos. Brasília, DF:

Secretaria de Direitos Humanos; Ministério da Educação. (2006)

BUBER, M. Eu e Tu. Trad. de Nilton A. von Zuben. 2a. edição. São Paulo: Cortez \& Moraes. (1979)

BUBER, M. Distanza Originaria e Relazione. In. II Princípio Dialógico e altri Saggi. Trad. Andréa Poma. 4a. ed. Torino, Itália: Edizione San Pablo. (1994)

BUBER, M. Do Diálogo e do Dialógico. Tradução Marta Ekstein de S. Queiroz e Regina Weinber. São Paulo: Perspectiva. (2009)

BUBER, M. O caminho do homem segundo o Hassidismo. Tradução Cláudia Abeling. São Paulo: É Realizações. (2011)

BUBER, M. Sobre Comunidade. Seleção e Introdução de Marcelo Dascal e Oscar Zimmermann. São Paulo: Perspectiva. (2012) 
COHN, G. Indiferença, nova forma de barbárie. In. NOVAES, Adauto (org.).

Civilização e Barbárie. São Paulo: Companhia das Letras. (2004)

GADAMER, H.-G. Verdade e método: traços fundamentais de uma hermenêutica filosófica. Trad. Flávio P. Meurer. 3. ed. Petrópolis: Vozes. (1999)

KLUBACK, W. Martin Buber: um exilado na terra de Israel. Trad. Marcelo P. Marques. In Revista Síntese Nova Fase. V. 20, pp. 323-339. (1993)

ZUBEN, N. A. Martin Buber: cumplicidade e diálogo. Bauru, SP: EDUSP. (2003). 